\title{
Extraction of an Impacted Foreign Body Bronchus in an Adult Using Flexible Bronchoscopy
}

\author{
Chandramouli M.T. ${ }^{1} \quad$ Nandakishore Baikunje ${ }^{1, \odot}$ \\ ${ }^{1}$ Department of Pulmonary Medicine, K.S. Hegde Medical Academy, \\ NITTE (deemed to be) University, Mangaluru, Karnataka, India
}

\author{
Rajesh Venkataram ${ }^{1} \quad$ Giridhar Hosmane ${ }^{1}$
}

Address for correspondence Chandramouli M.T., MBBS, MD, Department of Pulmonary Medicine, K.S. Hegde Medical Academy, NITTE (deemed to be) University, Mangaluru 575018, Karnataka, India (e-mail: mouli.aims@gmail.com).

\begin{abstract}
Keywords

- flexible bronchoscopy

- Fogarty catheter

- impacted foreign body

- left main bronchus
\end{abstract}

\section{Introduction}

Tracheobronchial foreign body aspiration (FBA) is rare but can be a potentially life-threatening event in adults. However, adults with risk factors such as drug abuse, alcohol intoxication, mental retardation, altered sensorium, convulsions, impaired cough, and swallowing reflex are predisposed to aspiration. Clinical presentation of FBA depends on the degree of obstruction, size, location, and length of time that the foreign body (FB) has been in the airway. Symptoms associated with FBA in adults may range from acute asphyxiation to cough, dyspnea, chest pain, wheeze. Retained FBs may lead to recurrent pneumonia, bronchiectasis, recurrent hemoptysis, pneumothorax, lung abscesses, pneumomediastinum, or other complications. ${ }^{1}$

Rigid bronchoscopy is the gold standard for diagnosis and management of FBA. FBA accounts for $0.16 \%$ to $0.33 \%$ of adult bronchoscopic procedures. ${ }^{2}$

\section{Case Report}

A 43-year-old man with no risk factors presented to the emergency department with a history of chewing betel nuts followed by the development of productive cough, shortness of breath, and chest pain for 3 days. Physical examination including respiratory system and laboratory results was unremarkable.

Flexible bronchoscopy was planned and performed under local anesthesia to diagnose the FBA. It showed betel nut (size approximately $15 \mathrm{~mm} \times 10 \mathrm{~mm}$ ) in the left main bronchus (LMB) at 3 to $4 \mathrm{~cm}$ from the carina with edema of surrounding mucosa and granulation tissue causing near-complete obstruction of the left main bronchus ( - Fig. 1). As the FB size was large and central in the location we planned rigid bronchoscopy for removal.

Under deep conscious sedation, achieved by propofol infusion in the presence of anesthesiologists. Rigid bronchoscopy published online May 11, 2021
DOI https://doi.org/ 10.1055/s-0041-1726679 ISSN 2582-4287

\footnotetext{
(c) 2021. Nitte (Deemed to be University).

This is an open access article published by Thieme under the terms of the Creative Commons Attribution-NonDerivative-NonCommercial-License, permitting copying and reproduction so long as the original work is given appropriate credit. Contents may not be used for commercial purposes, or adapted, remixed, transformed or built upon. (https://creativecommons.org/licenses/by-nc-nd/4.0/).

Thieme Medical and Scientific Publishers Pvt. Ltd. A-12, 2nd Floor, Sector 2, Noida-201301 UP, India
} 


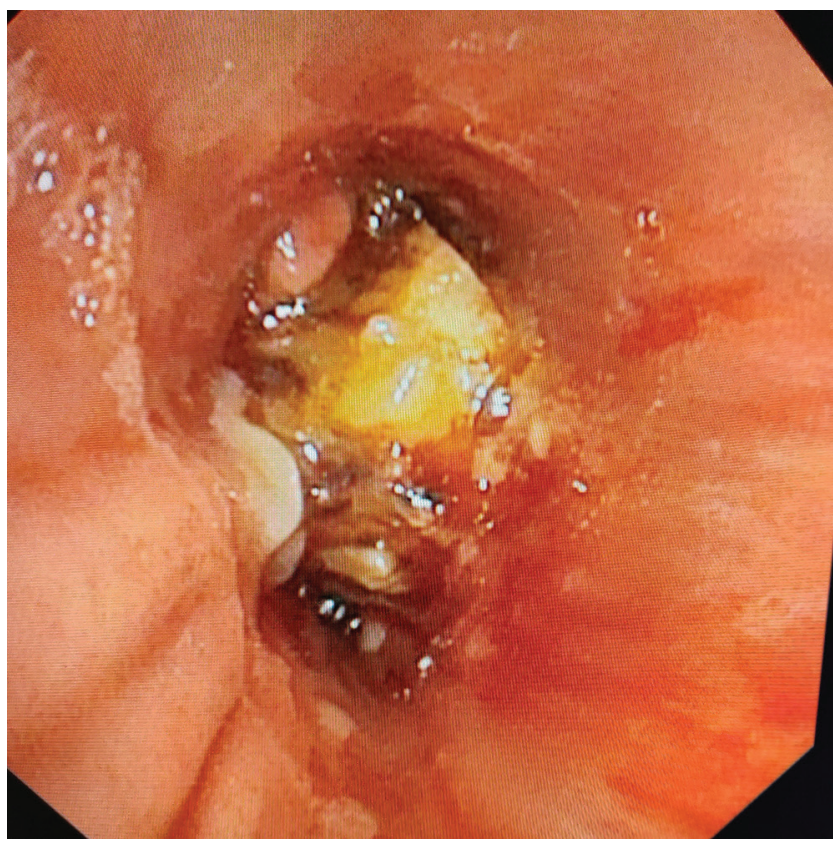

Fig. 1 Impacted foreign body in the distal left main bronchus with edematous mucosa.

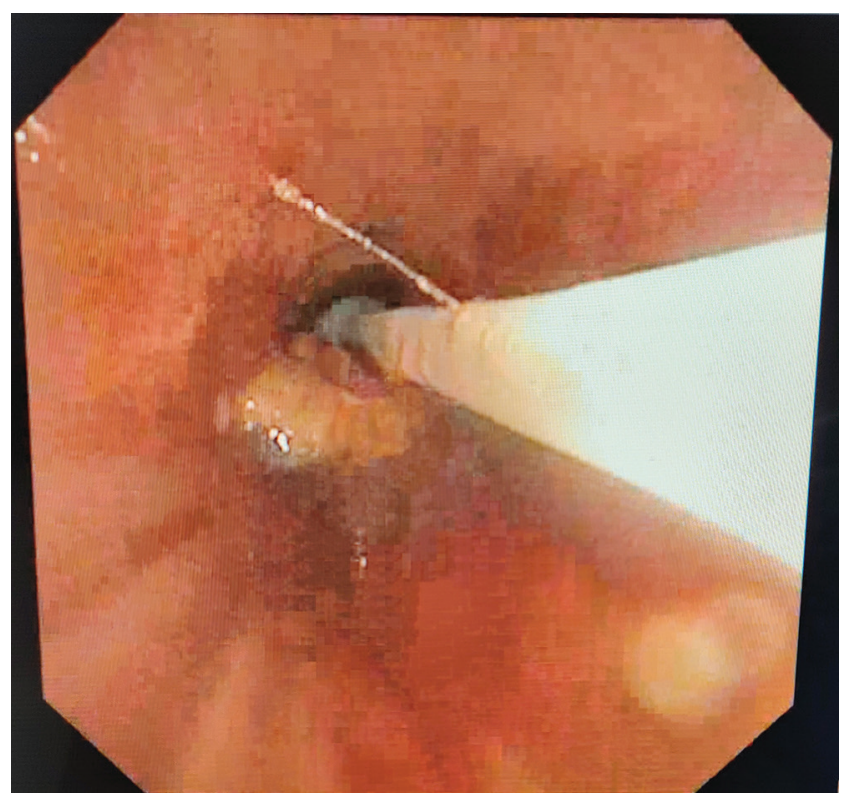

Fig. 2 Impacted foreign body dislodged with Fogarty balloon catheter.

was performed but we failed to extract the betel nut; as it was lodged in the distal LMB, rigid bronchoscopy forceps were not opening completely at that location and could not grasp the FB even after multiple attempts. Subsequently, we performed the flexible bronchoscopy under local anesthesia; Fogarty catheter was passed through the space available between the betel nut and superomedial wall of the bronchus so that balloon could be inflated just distal to the impacted betel nut. With moderate traction the FB was dislodged; however, due to edematous LMB, it took multiple attempts with Fogarty catheter to pull up the FB toward the carina ( - Fig. 2).

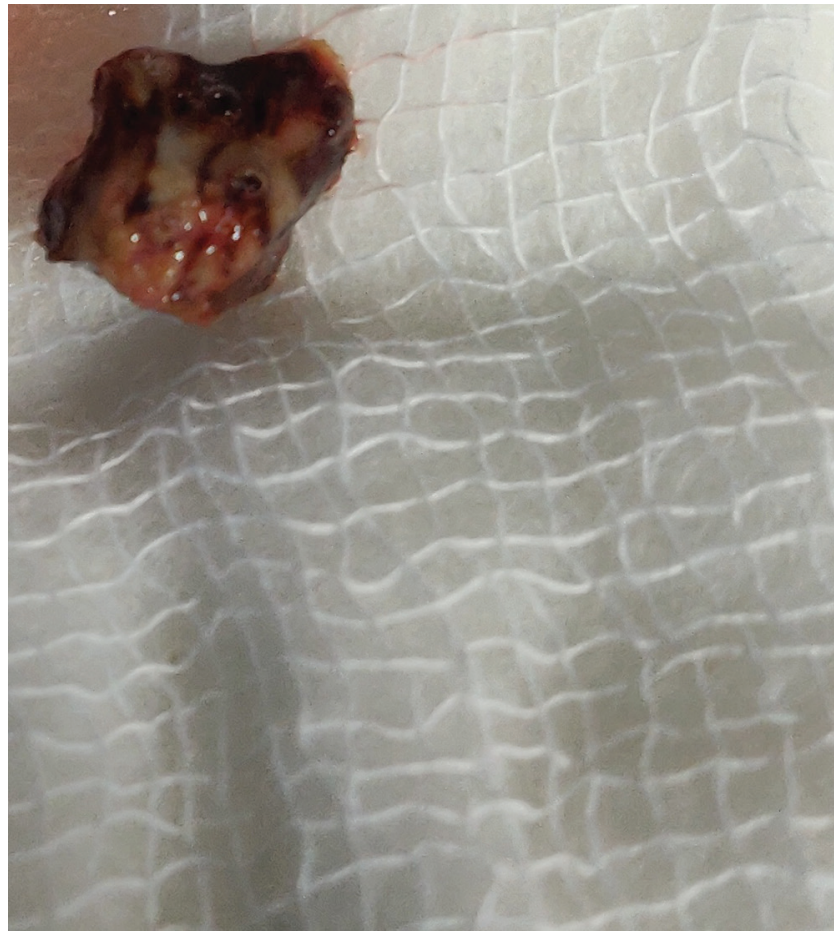

Fig. 3 Aspirated betel nut.

As the FB was moved toward carina, the plan was to retrieve it through the Dormia basket; however, the FB after reaching carina slipped into the right main bronchus and the patient developed a cough. Instantaneously, a flexible bronchoscope was removed and the patient brought out FB during that bout of cough ( - Fig. 3). Check bronchoscopy was performed; no fragments of betel nut were seen. The patient was then discharged after a day of observation for complications.

\section{Discussion}

FBA is rarer in adults than in children. According to data from the national security council, $80 \%$ of cases occur in patients aged less than 15 years, and 20\% in patients aged more than 15 years. ${ }^{3}$ Mortality from FBA is greatest in children younger than 1 year and adults older than 75 years. ${ }^{4,5}$ Chest radiography and computed tomography can provide information regarding the location and characteristics of the foreign body and assist in diagnosis. Rigid bronchoscopy is the gold standard for diagnosis and management of FBA.

The first successful endoscopic removal foreign body was performed by Gustav Killian in 1897. Following this, rigid bronchoscopy became the procedure of choice for removal of airway foreign bodies till the discovery of flexible bronchoscopy by Shigeto Ikeda in 1967 . Flexible bronchoscopy gradually supplanted rigid bronchoscopy as the most commonly used technique in adults, although rigid bronchoscopy remains the traditional gold standard, particularly in children. ${ }^{6}$

In adults, most of the aspirated FBs are lodged in the right bronchial tree. ${ }^{6}$ Inorganic FBs are inert, so patients may be asymptomatic for a prolonged period. In contrast, organic FBs 
can cause severe inflammation and tend to absorb water with the development of airway obstruction relatively earlier. ${ }^{7}$

The Fogarty catheter was originally developed for the removal of intravascular thrombi. Wiesel et al have reported the use of the Fogarty arterial embolectomy catheter for removing a tracheal foreign body in $1982 .{ }^{8}$ Fogarty catheter, if used effectively, saves time and possible injury to the mucosa by repeated use of forceps. Complications with the use of a Fogarty catheter are rare.,10 Baskets, grasping forceps, magnet extractors, YAG laser, and cryoprobes are available as accessories for FB removal via a flexible bronchoscope.

Rigid bronchoscopy is the modality of choice for the removal of $\mathrm{FB}$, but flexible bronchoscopy still has relevance as demonstrated in our case. Flexible bronchoscopy has the advantage of wider availability and lesser cost, and does not require general anesthesia. Various simple and easily available tools such as baskets, grasping forceps, and Fogarty catheter can be utilized via flexible bronchoscope to extract FB from the tracheobronchial tree.

\section{Conclusion}

A high index of suspicion and flexible bronchoscopy can ensure proper diagnosis and prompt intervention to avoid long-term sequel. Using a Fogarty balloon catheter and Dormia basket FB can be removed safely and successfully via a flexible bronchoscope.

\section{Conflict of Interest}

None declared.

\section{References}

1 al-Majed SA, Ashour M, al-Mobeireek AF, al-Hajjaj MS, Alzeer AH, al-Kattan K. Overlooked inhaled foreign bodies: late sequelae and the likelihood of recovery. Respir Med 1997;91(5):293-296

2 Sehgal IS, Dhooria S, Ram B, et al. Foreign body inhalation in the adult population: experience of 25,998 bronchoscopies and systematic review of the literature. Respir Care 2015; 60(10):1438-1448

3 National Safety Council. Report on injuries. Injury Facts. Accessed April 19, 2021 at www.library.nsc.org

4 Saki N, Nikakhlagh S, Rahim F, Abshirini H. Foreign body aspirations in infancy: a 20-year experience. Int J Med Sci 2009;6(6):322-328

5 Rafanan AL, Mehta AC. Adult airway foreign body removal. What's new? Clin Chest Med 2001;22(2):319-330

6 Baharloo F, Veyckemans F, Francis C, Biettlot MP, Rodenstein DO. Tracheobronchial foreign bodies: presentation and management in children and adults. Chest 1999; 115(5):1357-1362

7 Freiman MA, McMurray JS. Unique presentation of a bronchial foreign body in an asymptomatic child. Ann Otol Rhinol Laryngol 2001;110(6):495-497

8 Wiesel JM, Chisin R, Feinmesser R, Gay I. Use of a Fogarty catheter for bronchoscopic removal of a foreign body. Chest 1982;81(4):524

9 Carpenter RJ III, Snyder GG III. A complication in the use of a Fogarty catheter for foreign body removal during bronchoscopic management. Otolaryngol Head Neck Surg 1981; 89(6):998-1000

10 Saw HS, Ganendran A, Somasundaram K. Fogarty catheter extraction of foreign bodies from tracheobronchial trees of small children. J Thorac Cardiovasc Surg 1979;77(2):240-242 